\title{
Síndrome de Alström (OMIM 203800): Reporte del primer caso en Ecuador
}

\author{
Alström syndrome (OMIM 203800): Report of the first case in Ecuador \\ Síndrome de Alström (OMIM 203800): Relatório do primeiro caso no Equador
}

Byron Sancan Jalca (1) ${ }^{1}$, Daniel Cruz Montesinos (iD ${ }^{2}$

\begin{abstract}
1 HeredityEC, Jefe del Servicio de Genética Pediátrica. GuayaquilEcuador ; 2 Centro Médico Integral El Bienestar, CIEB. Médico del Servicio de Neurología Pediátrica. Guayaquil-Ecuador.
\end{abstract}

\section{Correspondencia a:}

Daniel Cruz Montesinos, dennis_cruz2002@yahoo.com

Recibido: 7 de mayo, 2021

Aceptado: 10 de septiembre, 2021

Publicado: 18 de noviembre, 2021

\section{CASO CLÍNICO}

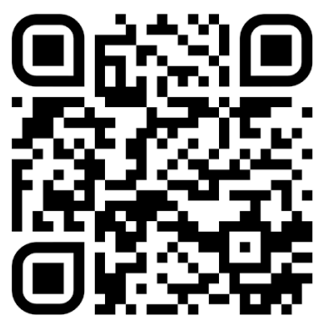

Escanea en tu dispositivo móvil o revisa este artículo en: https:// revistaclinicaguayaquil.org

\section{RESUMEN}

El síndrome de Alström (ALMS) es un raro desorden autosómico recesivo, caracterizado por una progresiva afectación multiorgánica que puede ocasionar una muerte precoz. Se trata de un preescolar masculino de tres años y siete meses de edad que presenta fotofobia, nistagmo, cardiomiopatía ventricular dilatada, retraso en el desarrollo psicomotor, trastorno del sueño, obesidad y epilepsia. Entre los diagnósticos diferenciales del síndrome genético se planteó al ALMS. Se realizó la secuenciación del exoma completo, en el gen ALMS1 se identificaron dos nuevas variantes c.5024delT (p.Phe1675SerfsTer16) en el exón 8 del gen ALMS1 y c.11717_1172 (OdelGTTG p.Val3906GlysfsTer) en el exón 18 del gen ALMS̄1. El ALMS, es una enfermedad extremadamente rara de expresión clínica heterogénea el estudio molecular es determinante para su diagnóstico.

Palabras clave: Síndrome de Alström; Trastornos de retraso en el desarrollo; Crisis epilépticas

\begin{abstract}
Alström syndrome (ALMS) is a rare autosomal recessive disorder characterized by progressive multiorgan involvement that can result in early death. The patient is a three-year seven-month old male who presents with photophobia, nystagmus, dilated ventricular cardiomyopathy, delayed psychomotor development, sleep disorder, obesity and epilepsy. Among the differential diagnoses of the genetic syndrome, ALMS was proposed. Whole exome sequencing was performed, in the ALMS1 gene, two new variants c.5024delT (p.Phe1675SerfsTer16) in exon 8 of the ALMS1 gene, and c.11717_1172 (0delGTTG p.Val3906GlysfsTer) in exon 18 of the ALMS1 gene were identified. ALMS is an extremely rare disease of heterogeneous clinical expression and the molecular study is determinant for its diagnosis.
\end{abstract}

Key words: Alström syndrome; Developmental delay disorder; Seizures

\section{RESUMO}

A síndrome de Alström (ALMS) é um distúrbio autossômico recessivo raro caracterizado por envolvimento progressivo de múltiplos órgãos que pode levar à morte precoce. O paciente é um préescolar masculino de três anos e sete meses de idade que apresenta fotofobia, nistagmo, cardiomiopatia ventricular dilatada, atraso no desenvolvimento psicomotor, distúrbio do sono, obesidade e 
epilepsia. Entre os diagnósticos diferenciais da síndrome genética, foi proposta a ALMS. Foi realizado o sequenciamento de todo o exome e duas novas variantes foram identificadas no gene ALMS1: c.5024delT (p.Phe1675SerfsTer16) no exon 8 do gene ALMS1 e c.11717_1172 (0delGTTG p.Val3906GlysfsTer) no exon 18 do gene ALMS1. O ALMS é uma doença extremamente rara de expressão clínica heterogênea e o estudo molecular é crucial para seu diagnóstico.

Palavras-chave: Síndrome de Alström; Transtornos de Atraso do desenvolvimento; Crise Epiléptica

\section{INTRODUCCIÓN}

El síndrome de Alström (ALMS) fue descrito por primera vez en Suecia por Carl-Henry Alström en 1959 (1). La incidencia exacta de este ultra raro desorden se desconoce, pero se estima una prevalencia de 1 en 10,000 a 1 en 1,000,000 (2-4).

El ALMS, es una enfermedad multiorgánica autosómica recesiva, de expresión clínica heterogénea, implacablemente progresiva, por ende, acorta la esperanza de vida de los pacientes, quienes rara vez exceden los 50 años (5). En su expresión clínica se destaca la obesidad troncal y el aceleramiento inicial en la curva de crecimiento infantil, en el adulto se observa talla baja, fotofobia, nistagmo, y pérdida auditiva neurosensorial. También presenta complicaciones endocrinológicas como diabetes tipo 2, hiperinsulinemia, hipertrigliceridemia, hipogonadismo hipogonadotrófico e hipotiroidismo. Más del $60 \%$ de los casos presentan miocardiopatía dilatada, que conlleva a insuficiencia cardiaca congestiva. En algunos pacientes se reportan anormalidades urológicas, insuficiencia renal y hepática, crisis epilépticas, retraso en el desarrollo psicomotor, infecciones respiratorias crónicas, hipertensión arterial, entre otros $(2,3)$.

El ALMS tiene su origen en una mutación en el gen ALMS1. Este gen está ubicado en el brazo corto $(p)$ del cromosoma 2 (2p13) y está compuesto por 23 exones que codifican una proteína de 4169 aminoácidos; se desconoce su función exacta, sin embargo, se ha propuesto que interviene en la función ciliar, el control del ciclo celular, el transporte intracelular y la diferenciación de adipocitos $(2,6)$.

A continuación se presenta el primer reporte de ALMS en Guayaquil, Ecuador.

\section{CASO CLÍNICO}

Preescolar masculino, mestizo, de tres años y siete meses de edad; producto de un primer embarazo, de una pareja joven y no consanguínea, nace a término, sin complicaciones. Por línea paterna se reporta un caso de síndrome de Down y trastorno de déficit de atención e hiperactividad y, por parte materna, un caso de esclerosis múltiple (Figura 1). En su evolución clínica, a los cuatro meses de edad se identifica nistagmo pendular e hipotonía generalizada, a los seis meses de edad se determina cardiopatía ventricular dilatada (CVD), interpretada como enfermedad de Kawasaki, por lo cual recibió inmunoglobulina; a los dos años y once meses se delimita un retraso global en el desarrollo psicomotor moderado, hipermetropía, astigmatismo e insomnio de conciliación y mantenimiento. Debuta con epilepsia a los tres años y dos meses, tipo de crisis: drop attacks, mirada fija, desconexión con el medio e hipertonía generalizada.

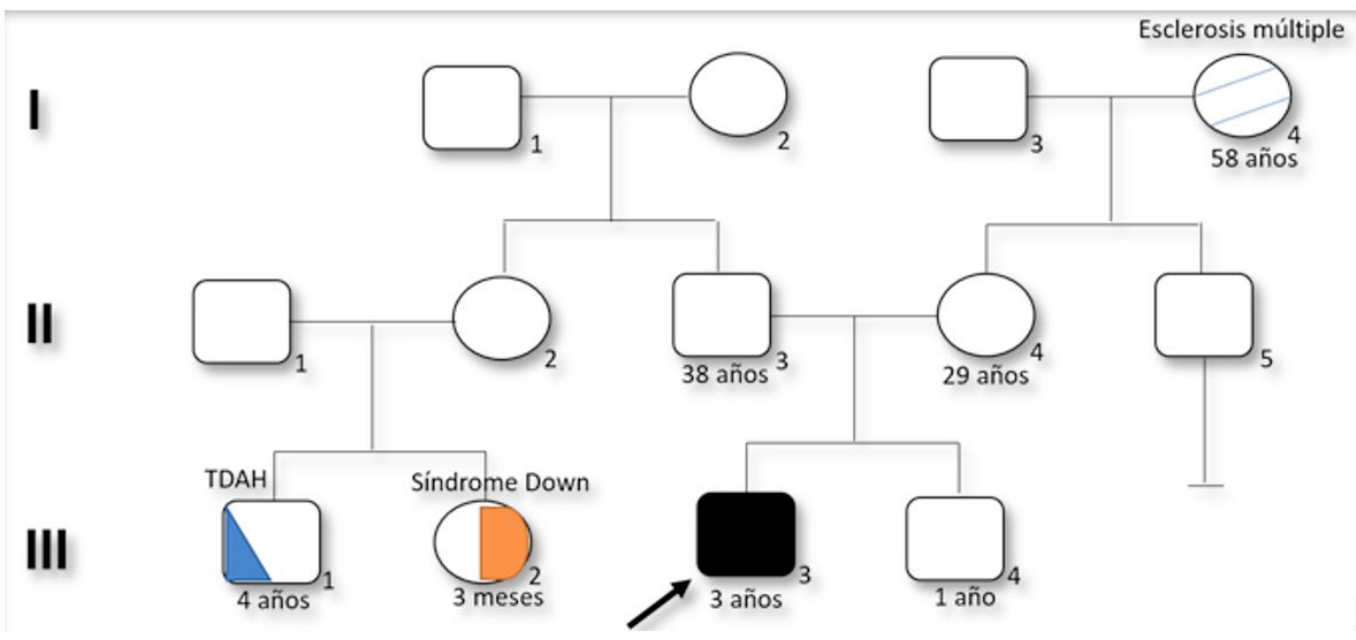

Figura 1. Árbol genealógico. 
Al examen físico, presenta un peso $28 \mathrm{~kg}$ (sobre percentil 97, obesidad), el perímetro cefálico es de $49 \mathrm{~cm}$ (percentil 50), su lenguaje es ininteligible, presenta fotofobia, escaso contacto ocular, impresiona baja visión, no responde al nombre, tiene un juego poco funcional, marcada inquietud, y no presenta noción del peligro (Figura 2).

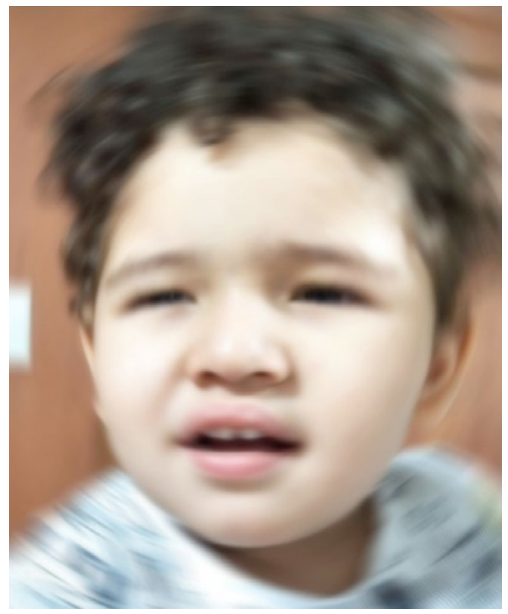

Figura 2. Preescolar masculino de 3 años y 11 meses con Síndrome Alstrom, presenta tendencia a cierre palpebral por fotofobia y fisuras palpebrales hacia abajo.

Entre los diagnósticos diferenciales del síndrome genético se planteó el ALMS. Se realizó la secuenciación del exoma completo, en el cual se determinó que el paciente es heterocigoto para la variante deleción: c.5024delT (p.Phe1675SerfsTer16) en el exón 8 del gen ALMS1. Además, el paciente es heterocigoto para la variante deleción c.11717_11720delGTTG, que se encuentra en el exón 18 del gen ALMS1 y se prevé que cause un cambio de marco de lectura y la consiguiente terminación prematura de la proteína (p.Val3906GlyfsTer2). En este paciente se confirma el diagnóstico genético del ALMS.

\section{DISCUSIÓN}

El ALMS es una enfermedad autosómica recesiva con variación intrafamiliar e interfamiliar que no tiene predisposición de género. Hasta el año 2020, a nivel mundial se han registrado 1200 casos y en su mayoría son reportes en países desarrollados $(2,4)$.

El diagnóstico de ALMS se realiza a través de la presencia de criterios mayores y menores. Los criterios mayores son: variante patogénica en un alelo ALMS1 o una historia familiar del síndrome, nistagmo, amaurosis, distrofia de conos y bastones. Son criterios menores, la obesidad y/o resistencia a la insulina y/o diabetes tipo 2, cardiomiopatía dilatada con insuficiencia cardiaca congestiva, pérdida auditiva, disfunción hepática, falla renal, estatura corta, hipogonadismo (hombres), hiperandrogenismo (mujeres) y otras variables de evidencia sustentada $(3,7)$.

El caso presentado cumple con los criterios mayores: variante del gen ALMS1, nistagmo, distrofia de conos y bastones; y menores: cardiomiopatía dilatada, obesidad, y otras variables de evidencia sustentada como retraso global en el desarrollo psicomotor, trastorno del sueño y crisis epilépticas.

La fotofobia y nistagmo pendular son mejor explicados por una pérdida de conos y desintegración de bastones, lo cual conllevará a una amaurosis precoz. Estos signos, están presente antes del primer año en el $100 \%$ de los casos $(2,8)$.

La CVD, se identifica en el $60 \%$ de los casos, puede presentarse a cualquier edad, pero es más frecuente durante la infancia y constituye la principal causa de muerte, por insuficiencia cardiaca congestiva (4). En un inicio, la CVD puede ser interpretada de etiología idiopática, o como una miocarditis infecciosa, una anomalía inmune o disfunción mitocondrial (6). En el presente caso, la CVD inicialmente fue interpretada como enfermedad de Kawasaki.

Un 20 a $46 \%$ de los casos, presentan un retraso en el desarrollo psicomotor $(4,8)$. En el caso que se presenta, el retraso en desarrollo psicomotor fue moderado. En cuanto a los trastornos del sueño, si bien no son tan frecuentes, también son descritos en el ALMS (2); en este caso se integró un insomnio mixto.

La obesidad identificada en este paciente es una característica cardinal del ALMS, el 95\% de los casos la presentan; se refiere que la mayor ganancia de peso se produce entre los 2 y 36 meses de edad $(4,5,8)$.

Un 10 a $20 \%$ de los casos presentan crisis epilépticas de ausencias $(4,5)$. En este paciente se identificaron dos tipos de crisis epilépticas: drop attacks, episodios de mirada fija e hipertonía generalizada.

Es menester destacar que el estudio genético molecular puede confirmar el diagnóstico de ALMS en un 70 a 80\% de los casos (3). En el 2020, Tahani y cols. reportaron 268 variantes, y el $96 \%$ de las mismas son sin sentido (inserción y selección) (5,9). Aproximadamente en el $40 \%$ de los casos la mutación ocurre en el exón 16, otras en el exón $10(23 \%)$ y en el exón $8(21 \%)(6,10)$. En el presente caso se encontró la variante en 
el exón 8 (c.5024delT), por lo que la proteína resultante probablemente carecerá de una repetición en tándem de AA de 25 a 34 regiones de repetición y de la región del motivo ALMS de la proteína. La variante identificada parece ser una variante nueva, ya que no ha sido reportada previamente en la literatura ni en bases de datos públicas de población. En la otra variante del exón 18 (c.11717_11720delGTTG), la proteína resultante probablemente carecerá de la región motivo de unión de la proteína ALMS; la variante identificada ha sido reportada en la base de datos dbSNP con un número de identificación rs932538480 y en la base de datos de agregación del genoma (gnomAD), como una variante rara con el AF más alto de 0.000003997; sin embargo, no se ha informado de homocigosidad (para esta variante). En la base de datos ClinVar, se ha informado de la importancia clínica de esta variante como patógena/probablemente patógena (RCV000673624.2) en el contexto del ALMS.

Los diagnósticos diferenciales que se deben considerar son el síndrome de Laurence Moon, Bardet Biedl (ciliopatia), amaurosis congénita de Leber, síndrome de Usher, síndrome de KearnsSayre, síndrome de Refsum $(3,10)$.

No existe un tratamiento específico para el ALMS, el manejo debe ser realizado por un equipo multidisciplinario y multiprofesional, enfocado en el síntoma específico de cada individuo (cardiología, oftalmología, endocrinología, neurología, ortopedista entre otros); el objetivo es disminuir la progresión a la disfunción multiorgánica y mejorar la longevidad y calidad de vida de estos pacientes $(5,11)$.

\section{CONCLUSIÓN}

El ALMS, es una enfermedad multiorgánica progresiva, extremadamente rara con una expresión clínica heterogénea y de diagnóstico diferencial amplio, bajo estos antecedentes el estudio molecular es concluyente para su diagnóstico. El diagnóstico temprano puede conducir a una mejor calidad de vida y sobrevida de los niños afectados, y permite un asesoramiento genético en el caso de futuros embarazos. El manejo multidisciplinario es determinante en su evolución.

\section{AGRADECIMIENTOS}

A los padres del paciente que autorizaron la presentación de este reporte científico sobre el caso de su hijo.

\section{REFERENCIAS}

1. Mastrapasqua SC. Síndrome de Alström: primer caso descripto en Argentina. Revista de Nefrología, Diálisis y Trasplante.2008; 28(1):17-20.

2. Joy $T$, Cao H, Black $G$, et al. Alström syndrome (OMIM 203800): a case report and literature review. Orphanet Journal of Rare Disease.2007; 2:49. DOI: 10.1186/1750-1172-2-49

3. Marshall JD, Maffei P, Becks S, et al. Clinical utility gene card for: Alström syndrome-update 2013. Eur J Hum Genet. 2013;21(11). DOI: 10.1038/ ejhg.2013.61

4. Marshall JD, Bronson RT, Collin GB, et al. New Alström Syndrome Phenotypes Based on the Evaluation of 182 Cases. Arch Intern Med. 2005;165(6):675-83. DOI: 10.1001/ archinte.165.6.675.

5. Tahani N, et al. Consensus clinical management guidelines for Alström Syndrome. Orphanet J Rare Dis 2020;15(253). DOI: 10.1186/s13023-02001468-8

6. Marshall JD, Maffei P, Collin GB, et al. Alström syndrome: Genetic and Clinical Overview. Curr Genomics. 2011;12(3):225-235. DOI: $10.2174 / 138920211795677912$

7. Shurygina MF, Parker MA, Schlechter $C L$, et al. $A$ case report of two siblings with Alstrom syndrome without hearing loss associated with two new ALMS1 variants. BMC Ophthalmol. 2019;19(246). DOI: 10.1186/s12886-019-1259-y

8. Mendoza-Caamal EC, Castro-Coyotl DM, Villanueva-Mendoza C, et al. Síndrome de Alström. Reporte de una familia mexicana, manejo multidisciplinario y revisión de la literatura. Rev Med Hosp Gen Mex. 2009;72(2):85-90.

9. Tsang $\mathrm{SH}$, Aycinena ARP, et al. Ciliopathy: Alström Syndrome. In; Tsang S., Sharma T. (eds) Atlas org inherited Retinal Diseases. Advances in Experimental Medicine and Biology. 2018;1085:180.

10. Wicher K, Bajon T, Wawrocka A, et al. Alström syndrome: A case report of the Polish family and a brief review of the differential diagnosis. Pediatria Polska. 2017;92:781-785.

11. Abdulaziz AK, Ayda Khalfan AA. ALSTROM Syndrome (Cases presentation and review of literature). Int J Ped \& Neo Heal. 2017;1(5):116121. DOI: $10.25141 / 2572-4355-2017-5.0116$

\section{ACERCA DE LOS AUTORES}

1. Byron Sancan Jalca. HeredityEC, Jefe del Servicio de Genética Pediátrica. GuayaquilEcuador.

ORCID: 0000-0003-3265-6795

2. Daniel Cruz Montesinos. Centro Médico Integral El Bienestar, CIEB. Médico del Servicio de Neurología Pediátrica. Guayaquil-Ecuador ORCID: 0000-0002-6417-9164 